\title{
ĐÁNH GIÁ THỰC TRANG NHIỄM VIÊM GAN B Ở NGƯỜI HIẾN MÁU TÌNH NGUYÊN LẦN ĐẦU TẠI BỆNH VIỆN TRUNG ƯƠNG QUÂN ĐộI 108 NĂM 2020
}

\author{
Nguyễn Xuân Thành ${ }^{1}$, Lê Huy Khôi ${ }^{1}$, \\ Ngô Quốc Việt ${ }^{1}$, Ngô Thị Ngà ${ }^{1}$, Phạm Thị Thu Hương ${ }^{1}$
}

TÓM TẮT.

Mục tiêu: Nghiên cứu đặc điểm và tỉ lệ nhiễm HBV ở người hiến máu tình nguyện lần đầu. Phương pháp: nghiên cứu cắt ngang, labo, mô tả, so sánh. Xác định HBsAg bằng test nhanh S్̛̃ BIOLINE-sắc ký miễn dich và xét nghiệm miễn dịch tự động ARCHITECT i2000-Miễn dịch hóa phát quang (Abbott). Kết quả và kết luận: tỉ lệ nhiễm $\mathrm{HBV}$ băng test nhanh là 2,7\% và tỉ lệ tăng thêm 0, $4 \%$ khi thực hiện trên Architect i2000SR. Độ tuổi nhiếm HBV có tỉ lệ cao nhất là <20 tuổi, tỉ lệ nam bị nhiễm HBV $100 \%$, tỉ lệ nhiễm chủ yếu là Sinh viên Cao đẳng và thuộc khư vực $\mathrm{Ba}$ vì (bán sớn địa). Tỉ lệ nhóm máu O nhiễm HBV cao nhất chiếm $49 \%$.

Tư khóa: HBV, HBsAg, test nhanh

\section{SUMMARY}

HBV TEST RESULTS IN BLOOD DONORS AT FIRST TIME IN 108 MILITARY CENTRAL HOSPITAL 2020

Objective: To study the characteristics and prevalence of HBV infection in first-time voluntary blood donors. Methods: cross-sectional research, labo, description, comparison. Determination of HBsAg by the rapid SD BIOLINE-immunochromatographic test and The ARCHITECT i2000SR immunoassay analyzer- the chemiluminescent microparticle immunoassay (Abbott). Results and conclusions: HBV infection rate by rapid test is $2.7 \%$ and the rate increases by $0.4 \%$ when performed on Architect i2000SR. The highest rate of HBV infection is $<20$ years old, the rate of men infected with HBV is $100 \%$, the rate of infection is mainly college students and in the $\mathrm{Ba} \mathrm{Vi}$ area (semi-highland). The rate of blood type $O$ infected with HBV is highest at $49 \%$.

Keywords: HBV, HBsAg, rapid test

\section{I. ĐẶT VẤN ĐỀ}

Viêm gan virus $B$ (HBV) là một trong những bệnh lây nhiễm phổ biến của thế giới với khoảng 2 tỷ người nhiễm HBV. HBV xâm nhập qua đường máu nên dễ dàng lây truyền rộng rãi bởi các sản phẩm máu kể cả các sản phẩm là tế bào và huyết tương. Bởi vậy, nhiều thập kỷ trước đây sự lây truyền HBV qua truyền máu và các sản

${ }^{1}$ Bệnh viện Trung ương Quân đội 108

Chịu trách nhiệm chính: Nguyễn Xuân Thành

Email: nguyenxuanthanh108@Gmail.com

Ngày nhận bài: 18.12.2020

Ngày phản biên khoa học: 22.01.2021

Ngày duyệt bài: 8.2 .2021 phẩm máu đóng vai trò quan trọng trong lây nhiễm HBV trên thế giới. Hiện nay, tình trạng lây nhiễm HBV qua truyền máu vẫn là mối đe dọa ở các nước đang phát triển, nơi có tỉ lệ nhiễm HBV cao và quy trình sàng lọc máu chưa chă̆t chẽ $[1,2]$. Việt Nam là một nước đang phát triển có tỉ lệ nhiếm HBV khá cao 10-20\% [3], mặc dù Máu và các sản phẩm từ máu trước khi được sử dụng đã được xét nghiệm sàng lọc theo qui trình nghiêm ngăt và chă̆t chẽ, song tỉ lê nhiếm HBV dựa trên dấu ấn sinh học HBsAg vấn có ý nghĩa cực kỳ quan trọng trong chuyên ngành truyền máu. Bởi vậy trong nghiên cứu này chúng tôi đánh giá tỉ lệ và đặc điểm nhiễm HBV ở người hiến máu tình nguyện lần đầu tại Bệnh viện Trung ương Quân đội (twqđ) 108.

\section{II. ĐỐl TƯƠNGG VÀ PHƯƠNG PHÁP NGHIÊN CỨU}

2.1. Đối tượng nghiên cứu. Nghiên cứu đánh giá trên 1858 người đủ tiêu chuẩn đăng ký hiến máu nhân đạo theo TT 26/2013/TT-BYT và tham gia hiến máu lần đầu. Tiêu chuẩn loại trừ là những người đăng ký hiến máu không đủ theo tiêu chuẩn TT 26/2013/TT-BYT hoặc những người đã từng hiến máu trước đây.

2.2. Phương pháp nghiên cứu. Nghiên cứu theo phương pháp cắt ngang, labo, mô tả, so sánh và đánh giá.

Các chỉ số của người hiến máu được thu thập qua phiếu tình nguyện hiến máu nhân đạo.

Kỹ thuật phát hiện HBsAg: sử dụng test nhanh SD BIOLINE, nguyên lý sắc ký miễn dịch. Các bước thực hiện theo hướng dẫn của nhà sản xuất. Sử dụng máy Architect i2000SR theo nguyên lý miển dịch hóa phát tại labo xét nghiệm sàng lọc khoa Truyền máu Bệnh viện TWQĐ108, các bước thực hiện theo hướng dẩn của nhà sản xuất.

2.3. Xử lý số liệu: phần mềm SPSS v. 20

2.4. Y đức: Các các nhân tình nguyện tham gia hiến máu và làm xét nghiệm sàng lọc. Kết quả xét nghiệm được thông báo đến từng cá nhân và đảm bảo nguyên tắc theo hướng dẫn của Thông tư 26/2013/TT-BYT.

III. KẾT QUẢ VÀ BÀN LUÂ̂N

3.1. Tỉ lệ nhiễm HBV bằng test nhanh 
Bảng 1: Tỉ lệ HBsAg bằng test nhanh ở người hiến máu tình nguyện lần đầu

\begin{tabular}{|c|c|c|}
\hline \multirow{2}{*}{ Kết quả } & \multicolumn{2}{|c|}{ HBsAg } \\
\cline { 2 - 3 } & $\mathbf{n}$ & $\mathbf{\%}$ \\
\hline Âm tính & 1807 & 97.3 \\
\hline Dương tính & 51 & 2.7 \\
\hline Tống & $\mathbf{1 8 5 8}$ & $\mathbf{1 0 0 . 0}$ \\
\hline
\end{tabular}

Kết quả từ bảng 1 cho thấy, tỉ lê nhiễm HBV trong nhóm nghiên cứu là 51 trường hợp chiếm $2,7 \%$. Tỉ lệ nhiễm HBV này là khá thấp so với tî lế nhiễm HBV trong cộng đồng (10-15\%). Song tỉ lệ nhiễm này cũng phản ánh các trường hợp đủ tiêu chí tham gia hiến máu chủ yếu nằm trong các nhà trường, cơ quan, bởi vậy tỉ lệ lưu hành của HBV là không cao.

3.2. Đặc điểm nhiễm HBV của nhóm nghiên cứu

\section{Bảng 2: Phân bố nhiếm HBV theo nhóm tuối}

\begin{tabular}{|c|c|c|c|c|c|c|}
\hline \multirow{2}{*}{ Tuổi } & \multicolumn{6}{|c|}{ HBsAg test nhanh } \\
\cline { 2 - 7 } & \multicolumn{2}{|c|}{ Am tính } & \multicolumn{2}{|c|}{ Dương tính } & \multicolumn{2}{c|}{ Tống } \\
\cline { 2 - 7 } & $\mathbf{n}$ & $\mathbf{\%}$ & $\mathbf{n}$ & $\mathbf{\%}$ & $\mathbf{n}$ & $\mathbf{\%}$ \\
\hline$<20$ & 1339 & $74.1 \%$ & 40 & $78.4 \%$ & 1379 & $74.2 \%$ \\
\hline $21-30$ & 361 & $20.0 \%$ & 11 & $21.6 \%$ & 372 & $20.0 \%$ \\
\hline $31-40$ & 73 & $4.0 \%$ & 0 & $0.0 \%$ & 73 & $3.9 \%$ \\
\hline$>40$ & 34 & $1.9 \%$ & 0 & $0.0 \%$ & 34 & $1.8 \%$ \\
\hline Tống & $\mathbf{1 8 0 7}$ & $\mathbf{1 0 0 . 0 \%}$ & $\mathbf{5 1}$ & $\mathbf{1 0 0 . 0 \%}$ & $\mathbf{1 8 5 8}$ & $\mathbf{1 0 0 . 0} \%$ \\
\hline
\end{tabular}

Đế đánh giá mức độ phân bố nhiếm HBV trong nhóm hiến máu nhân đạo, chúng tôi phân các nhóm tuổi, kết quả trong bảng 2 cho thấy, trong 51 trường hợp dương tính với HBV bằng test nhanh thì tỉ lệ nhiễm ở nhóm tuổi $<20$ tuổi là cao nhất chiếm $78,4 \%$ so với các nhóm tuổi còn lại. Điều này có thể do tỉ lê số người dưới 20 tuổi chiếm tỉ lệ lớn nhất $74,2 \%$, trong khi đó độ tuổi $>40$ chỉ chiếm có $1,8 \%$ và không có trường hợp nào dương tính với HBV.

Bảng 3: phân bố nhiếm HBV theo giới

\begin{tabular}{|c|c|c|c|c|c|c|}
\hline \multirow{2}{*}{ Giới tính } & \multicolumn{9}{|c|}{ Äm tính } & \multicolumn{2}{c|}{ Dương tính } & \multicolumn{2}{c|}{ Tống } \\
\cline { 2 - 7 } & $\mathbf{n}$ & $\mathbf{\%}$ & $\mathbf{n}$ & $\mathbf{\%}$ & $\mathbf{n}$ & $\mathbf{\%}$ \\
\cline { 2 - 7 } & 1676 & $92.8 \%$ & 51 & $100.0 \%$ & 1727 & $92.9 \%$ \\
\hline Nam & 131 & $7.2 \%$ & 0 & $0.0 \%$ & 131 & $7.1 \%$ \\
\hline Nữ & $\mathbf{1 8 0 7}$ & $\mathbf{1 0 0 . 0 \%}$ & $\mathbf{5 1}$ & $\mathbf{1 0 0 . 0 \%}$ & $\mathbf{1 8 5 8}$ & $\mathbf{1 0 0 . 0} \%$ \\
\hline Tống & &
\end{tabular}

Kết quả phân bố của HBV theo giới được thể hiện trong bảng 3, số liệu này cho thấy, trong 51 trường hợp dương tính với HBV tất cả đều là nam chiếm $100 \%$. Tỉ lệ này cũng khá hợp lý trong nhiễm HBV , trong nghiên cứu này tỉ lệ nam cũng chiếm đa số $92,7 \%$, hơn nữa nhiều nghiên cứu trước đây cũng cho thấy tỉ lệ nhiễm HBV ở nam cao hơn nữ và liên quan nhiều đến các yểu tố nguy cơ, phơi nhiếm.

Bảng 4: phân bố nhiễm HBV theo nghề nghiệp

\begin{tabular}{|c|c|c|c|c|c|c|}
\hline \multirow{2}{*}{ Nghề nghiệp } & \multicolumn{6}{|c|}{ HBsAg test nhanh } \\
\cline { 2 - 7 } & $\mathbf{A}$ & $\mathbf{A}$ tính & $\mathbf{0}$ & $\mathbf{0}$ & \multicolumn{2}{c|}{ Tớng } \\
\cline { 2 - 7 } & $\mathbf{n}$ & 197 & $\mathbf{n}$ & $\mathbf{\%}$ & $\mathbf{n}$ & $\mathbf{\%}$ \\
\hline Công chức & 197 & $10.9 \%$ & 2 & $3.9 \%$ & 199 & $10.7 \%$ \\
\hline Sinh viên cao đăng & 532 & $29.4 \%$ & 36 & $70.6 \%$ & 568 & $30.6 \%$ \\
\hline Sinh viên đại học & 1078 & $59.7 \%$ & 13 & $25.5 \%$ & 1091 & $58.7 \%$ \\
\hline Tống & $\mathbf{1 8 0 7}$ & $\mathbf{1 0 0 . 0 \%}$ & $\mathbf{5 1}$ & $\mathbf{1 0 0 . 0 \%}$ & $\mathbf{1 8 5 8}$ & $\mathbf{1 0 0 . 0 \%}$ \\
\hline
\end{tabular}

Tìm hiểu thêm về yếu tố nguy cơ nghề nghiệp, kết quả ở bảng 4 cho thấy, tỉ lệ nhiềm HBV cao nhất ở nhóm sinh viên cao đẳng có 36 trường hợp chiếm $70,6 \%$, tiếp đến là sinh viên đại học chiếm $25,5 \%$. Tỉ lệ này cũng liên quan nhiều đến các yếu tố nguy cơ như nhận thức, hành vi và các yếu tố nguy cơ khác có thể gây lây nhiếm HBV

Bảng 5: phân bố nhiếm HBV theo vùng

\begin{tabular}{|c|c|c|c|c|c|c|}
\hline \multirow{2}{*}{ Khu vực } & \multicolumn{6}{|c|}{ HBsAg test nhanh } \\
\cline { 2 - 7 } & $\mathbf{2}$ Am tính & \multicolumn{2}{c|}{ Dương tính } & \multicolumn{2}{c|}{ Tống } \\
\cline { 2 - 7 } & $\mathbf{n}$ & $\mathbf{\%}$ & $\mathbf{n}$ & $\mathbf{\%}$ & $\mathbf{n}$ & $\mathbf{\%}$ \\
\hline Ba vì & 568 & $31.4 \%$ & 38 & $74.5 \%$ & 606 & $32.6 \%$ \\
\hline Nội thành Hà Nội & 143 & $7.9 \%$ & 0 & $0.0 \%$ & 143 & $7.7 \%$ \\
\hline Hưng yên & 1096 & $60.7 \%$ & 13 & $25.5 \%$ & 1109 & $59.7 \%$ \\
\hline Tống & $\mathbf{1 8 0 7}$ & $\mathbf{1 0 0 . 0 \%}$ & $\mathbf{5 1}$ & $\mathbf{1 0 0 . 0 \%}$ & $\mathbf{1 8 5 8}$ & $\mathbf{1 0 0 . 0 \%}$ \\
\hline
\end{tabular}


Đánh giá mức phân bố nhiễm HBV theo vùng (đồng bằng, thành thị và vùng bán sơn địa), kết quả ở bảng 5 cho thấy, tỉ lệ dương tính ở khu vực Ba vì chiếm tỉ lệ cao nhất với 38 trường hợp chiếm $74,5 \%$, vùng Hưng Yên có 13 trường hợp chiểm 25,5\%. Trong khi đó, ở nội đô Hà Nội không có trường hợp nào. Mặc dù tỉ lệ người tham gia nghiên cứu là khá chênh lệch song tỉ lệ nhiễm HBV cũng phản ánh phần nào thực trạng lưu hành HBV trong các vùng miền và các yếu tố nguy cơ lây nhiễm trong cộng đồng.

Bảng 6: Phân bố nhiễm HBV theo nhóm máu

\begin{tabular}{|c|c|c|c|c|c|c|}
\hline \multirow{2}{*}{ Nhóm máu } & \multicolumn{6}{|c|}{ ABsAg test nhanh } \\
\cline { 2 - 7 } & $\mathbf{n}$ & $\mathbf{0}$ & $\mathbf{n}$ & $\mathbf{\%}$ & $\mathbf{n}$ & $\mathbf{\%}$ \\
\cline { 2 - 7 } & 394 & $21.8 \%$ & 6 & $11.8 \%$ & 400 & $21.5 \%$ \\
\hline $\mathrm{A}$ & 105 & $5.8 \%$ & 2 & $3.9 \%$ & 107 & $5.8 \%$ \\
\hline $\mathrm{AB}$ & 543 & $30.0 \%$ & 18 & $35.3 \%$ & 561 & $30.2 \%$ \\
\hline $\mathrm{B}$ & 765 & $42.3 \%$ & 25 & $49.0 \%$ & 790 & $42.5 \%$ \\
\hline $\mathrm{O}$ & $\mathbf{1 8 0 7}$ & $\mathbf{1 0 0 . 0} \%$ & $\mathbf{5 1}$ & $\mathbf{1 0 0 . 0} \%$ & $\mathbf{1 8 5 8}$ & $\mathbf{1 0 0 . 0} \%$ \\
\hline Tống & &
\end{tabular}

Đánh giá phân bố nhiễm HBV theo nhóm máu, kết quả ở bảng 6 cho thấy, tỉ lệ nhiễm HBV cao thuộc nhóm máu $O$ sau đó là nhóm máu $B$ và thây nhất là nhóm máu $A B$. Song tỉ lệ này cũng chưa là con số đại diện trong cộng đồng vì số người ở các nhóm máu tham gia hiến máu khác nhau, chiếm ưu thể luôn là nhóm máu $\mathrm{O}$.

Bảng 7: tỉ lệ không phát hiện HBsAg bằng test nhanh

\begin{tabular}{|c|c|c|c|c|c|c|}
\hline \multirow{2}{*}{$\begin{array}{c}\text { HBsAg Miễn dịch hóa } \\
\text { phát quang }\end{array}$} & \multicolumn{6}{|c|}{ HBsAg test nhanh } \\
\cline { 2 - 7 } & $\mathbf{n}$ & $\mathbf{0}$ & $\mathbf{n}$ & $\mathbf{0}$ & $\mathbf{n}$ & $\mathbf{\%}$ \\
\cline { 2 - 7 } & 1799 & $99.6 \%$ & 51 & $100.0 \%$ & 1850 & $99.6 \%$ \\
\hline Äm tính & 8 & $0.4 \%$ & 0 & $0.0 \%$ & 8 & $0.4 \%$ \\
\hline Dướng tính & $\mathbf{1 8 0 7}$ & $\mathbf{1 0 0 . 0 \%}$ & $\mathbf{5 1}$ & $\mathbf{1 0 0 . 0} \%$ & $\mathbf{1 8 5 8}$ & $\mathbf{1 0 0 . 0} \%$ \\
\hline Tống & &
\end{tabular}

Vì HBV lây theo đường máu nên để đảm bảo một đơn vị máu thực hiện truyền máu an toàn việc sàng lọc HBV cần đảm bảo độ nhạy và độ chính xác cao mà test nhanh phát hiện HBsAg không đảm bảo được. Kết quả bảng 7 cho thấy, khi làm kỹ thuật miễn dịch hóa phát quang với độ nhạy gần như tuyệt đối được sử dụng phát hiện HBsAg thì trong 1807 ca âm tính có 8 trường hợp dương tính chiếm $0,4 \%$ tổng số được đánh giá. Tỉ lệ dương tính cho thấy, khả năng sàng lọc của test nhanh HBsAg còn nhiêu hạn chế, mặc dù có nhiều ưu điểm trong xét nghiệm sàng lọc cộng đồng.

\section{KẾT LUẬN}

Kết quả nghiên cứu trên 1858 người hiến máu tình nguyện cho thây, tỉ lệ nhiễm HBV bằng test nhanh là $2,7 \%$ và tỉ lệ tăng thêm $0,4 \%$ khi làm phương pháp hóa miển dịch huỳnh quang. Lứa tuổi chiếm tî lệ HBV cao nhất là <20 tuổi, tỉ lệ nam bị nhiễm HBV $100 \%$, tỉ lệ nhiễm chủ yếu là Sinh viên $\mathrm{Cao}$ đẳng và thuộc khu vực $\mathrm{Ba}$ vì (bán sơn địa). Tỉ lệ nhóm máu $\mathrm{O}$ nhiễm HBV cao nhất chiếm 49\%.

\section{TÀI LIỆU THAM KHẢO}

1. Candotti D, Allain JP. Transfusion-transmitted hepatitis B virus infection. J Hepatol 2009; 51: 798-809.
2. Allain JP, Candotti D. Diagnostic algorithm for HBV safe transfusion. Blood-Transf 2009; 7;174-82.

3. https://moh.gov.vn/chuong-trinh-muc-tieuquoc-gia/ asset_publisher/ 7ng11fEWgASC/ content/ viet-nam-co-ty-le-nhiem-virus viem-ganb-cao-nhat-the-gioi. guyen VTT, Law MG, Dore GJ. An enormous hepatitis $B$ virus-related liver disease burden projected in Vietnam by 2025 . Liver Int. 2008; 28:525-531.

4. Hipgrave DB, Van NT, Huong VM, et al. Hepatitis B infection in rural Vietnam and the implications for a national program of infant immunisation. Am J Trop Med Hyg. 2003;69:288-294.

5. Vien $\mathbf{C}$, Nguyen $\mathbf{T}$, Dinh $\mathbf{S}$. Investigation of hepatitis B virus infection among emplyees in Nha Trang City. J Hyg Prev Med. 1996;6(4):34-40 guyen VTT, Law MG, Dore GJ. An enormous hepatitis B virus-related liver disease burden projected in Vietnam by 2025 . Liver Int. 2008;28:525-531.

6. Hipgrave DB, Van NT, Huong VM, et al. Hepatitis B infection in rural Vietnam and the implications for a national program of infant immunisation. Am J Trop Med Hyg. 2003;69:288-294.

7. Vien $C_{\text {, Nguyen }} \mathbf{T}$, Dinh $\mathbf{S}$. Investigation of hepatitis B virus infection among emplyees in Nha Trang City. J Hyg Prev Med. 1996;6(4):34-40

8. Nguyen VTT, Law MG, Dore GJ. An enormous hepatitis B virus-related liver disease burden projected in Vietnam by 2025 . Liver Int. 2008;28:525-531.

9. Nguyen VT-T, McLaws M-L, Dore G. Highly endemic hepatitis B infection in rural Vietnam. J Gastroenterol Hepatol. 2007;22:2093-2100. 